帯域焼鈍法による所望方位を有する Mo 単結晶の作製

\author{
上平 一茂, 本多 均一, 藤井 忠行 \\ 金属材料技術研究所， 305 つく谋市千現1-2-1.

\section{Preparation of Molybdenum Single Crystal with a Desired Orientation by Means of Zone Annealing}

\author{
Kazushige Kamihira, Kinichi Honda and Tadayuki Fujii \\ National Research Institute for Metals, 1-2-1 Sengen, Tsukuba 305.
}

Received March 31, 1997

\title{
SYNOPSIS
}

A new technique for preparation of molybdenum single crystal with a desired orientation has been proposed. The technique was performed as follows; first, a specimen with a comb shape was mechanically fabricated from hot-rolled sheet with various rolling procedures and reductions. Then the edge of specimen with a comb shape was locally heated by the optical-beam image furnace in order to make some secondary recrystallized grains with various orientations. After the secondary recrystallized grains were mechanically eliminated except for a secondary grain having a desired orientation, the specimen was zone-annealed at $2000-2200^{\circ} \mathrm{C}$ at the zone-speed of $5 \mathrm{~mm} /$ $\mathrm{hr}$ to grow the secondary grain. Consequently, molybdenum single crystal with a desired crystallographic orientation can easily be produced.

\section{KEY WORDS}

molybdenum, zone annealing, single crystal with a desired orientation, secondary recrystallized grain

\section{1 緒 言}

著者らはこれまでに 2 次再結晶粒成長（異常結晶粒 成長) 現象を基本的に支配する金属学的諸因子（ドー プ元素および量, 加工および1次再結晶集合組織, 1 次再結晶粒径および形状）について検討し1-7)，これら 上記諸因子を制御することにより複雑形状を有する高 融点金属 Mo，W およびこれらの合金の大型単結晶材 料の製造に成功している8-10). 近年, 太陽熱口ケットの ノズル材料, 熱電子発電用のエミッター, コレタター 材料やレーザ反射鏡材料等の樣々な機能材料分野人 Mo, W 単結晶が利用されつつある. また, 単結晶材料 に特有な結晶方位の異方性から生じる材料の物理的, 化学的および機械的な特性を十分に発揮させるために, 特定方位（結晶面，方向）を有する単結晶材料が求め られてきている。しかし，特定方位を有する金属単結
晶材料の製造技法 ${ }^{1,12)}$ については今までにいくつかの 研究や検がなされているが，固相法 (再結晶法)によ り方位制御を目的とした高融点金属単結晶作製技法は 皆無である。

本研究では，上述の特定方位を有する単結晶を得る ための手段として，帯域焼鈍技法による2 次再結晶粒 方位を制御したMo 単結晶の作製が可能か否かについ て検討した。

\section{2 実験方法}

出発䒺材は Caおよび $\mathrm{Mg}$ を総量で 0.005 mass \%添加 したMo粉体を一般的な粉末治金法によって厚さ $20 \mathrm{~mm}$ の焼結インゴットを作製後，1次再結晶集合組 織を制御することを目的としてストレート圧延 (一方 向圧延)，クロス圧延 (交差圧延) の 2 種類の圧延方法 
ならびに圧延率を $70 \%$ と $90 \%$ とした圧延板である. 実 験に供した試料はこれらの圧延板から圧延方向を長さ 方向として Fig.1のように一方に櫛状に切り込みを入 れた. 次にこれらの試料に対して 2 次再結晶核粒を試 料端部に作成するために光ビーム帯域精製装置を用い て均熱加熱を目的に 1 分間に 7 回転の速度で回転させ ながら $\mathrm{Ar}$ ガス雾囲気中にて $2000^{\circ} \mathrm{C}, 1$ 時間の集光加熱 を局部的に施した.

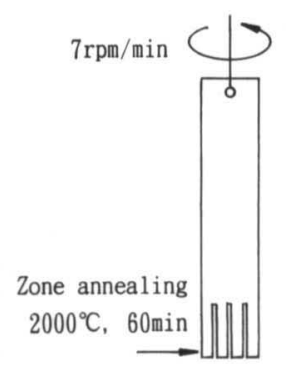

$a^{\prime}$
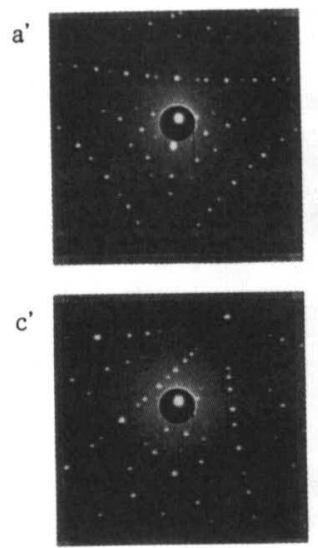

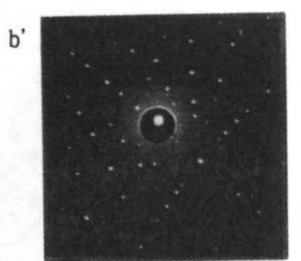

$d^{\prime}$

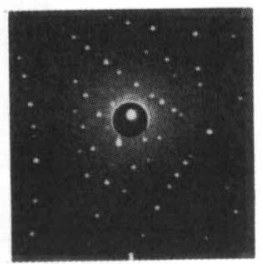

Fig. 1 Schematic drawing of the zone annealing process by the optical beam image heating. Laue patterns of a', b', c' and $d^{\prime}$ correspond to the secondary recrystallized grains of a to $d$ shown in the drawing.

その結果, Fig.1に見られるように切り込みにより分 割された試料端部, $\mathrm{a} \sim \mathrm{d}$ に 2 次再結晶粒を得た. 以後, この粒をここでは 2 次再結晶核粒と定義する。また， Fig.1下部にX 線ラウエ背面反射写真を示してあるが, 写真 $\mathrm{a}^{\prime} \sim \mathrm{d}^{\prime}$ は核粒の $\mathrm{a} \sim \mathrm{d}$ に対応しておりこれらの核粒 が異なる方位を示すことを確認した，また，1次再結 晶集合組織については各種圧延板を $1500^{\circ} \mathrm{C}, 1$ 時間焼 鈍した後, 極点図形を作成することにより解析した。 さらに, 本実験目的である所望方位を有する単結晶材 料を得るために以下のような操作を行った. まず各種
圧延方法, 圧延率の異なる試料を上述した局部加熱に より試料端部に複数の 2 次再結晶核粒を作製後, 所望 方位を選択し，他の核粒方位を機械的に除去した，次 に試料を $2000 \sim 2200^{\circ} \mathrm{C}$ の温度に保ちながら $5 \mathrm{~mm} / \mathrm{hr}$ の 引き下げ速度で帯域焼鈍を施し, 選択した所望核粒と 同一方位を有する単結晶の作製を試みた。

\section{3 実験結果および考察}

本実験においては, 圧延方法ならびに圧延率を変え て作製したドープMo压延板を用い，Fig.1に示した形 状をもつ試料に集中的な高温焼鈍を施すことによって， どのような 2 次再結晶核粒 (ここでは, 結晶方位の異 なる複数の 2 次再結晶粒) 方位が出現するか調べた. 次に, 得られた核粒から所望方位粒を選択して帯域焼 鈍法による単結晶の作製を試みた.

Fig.2,3にそれぞれストレートおよびクロス圧延試料 の 1 次再結晶集合組織と試料端部を集光加熱により得 られた 2 次再結晶核粒方位を $\{200\}$ 極点図で示す.ま た, Table 1ならびに Table 2 には得られた集合組織の 方位関係の結果について整理して示す.1次再結晶集 合組織は圧延方法および圧延率の違いにもかかわらず BCC 金属で典型的に出現する 3 成分のうち $\{100\}$ $<011>,\{111\}<112>$ 方位の主要な 2 成分によって構成 されている 13-15). 圧延率 70\%のストレート圧延の場合 は 1 次再結晶集合組織は主成分として $\{100\}<011>$ 方 位で構成されているものの Fig.2 およびTable 1 の結果 が示すように他の成分を含み, 一般的に集積度が低い 方位分布をとっている. 圧延率 $90 \%$ の場合には 1 次再 結晶集合組織は主成分として $\{111\}<112>$ 方位, 副成 分として $\{100\}<011>$ 方位の 2 成分からなる集積度の 高い方位成分によって構成されている.

ストレート圧延における特徵的なことは圧延率の違 いにより出現する 2 次再結晶核粒の結晶方位が異なる ことで, 圧延率 70\%では $\{100\}<001>$ およ゙ $\{310\}$ $<001>$ 近傍方位を中心として分散した方位が発達し， 圧延率 90\%の場合は $\{112\}<111>,\{123\}<111>$ 近傍 方位を中心として分散し, 発達した方位粒として整理 することができる。この結果, 得られた 2 次再結晶粒 方位成分は 1 次再結晶集合組織の主成分から隔てた弱 成分より出現しており, これらの方位成分が 2 次再結 晶粒として発達したことを示している ${ }^{10.16}$. 一方, ク ロス圧延ではFig.3に示したように, 1次再結晶集合組 織は圧延率70\%および $90 \%$ のどちらの場合も主成分と して $\{100\}<011>$ 方位, 副成分として $\{111\}<112>$ 方 

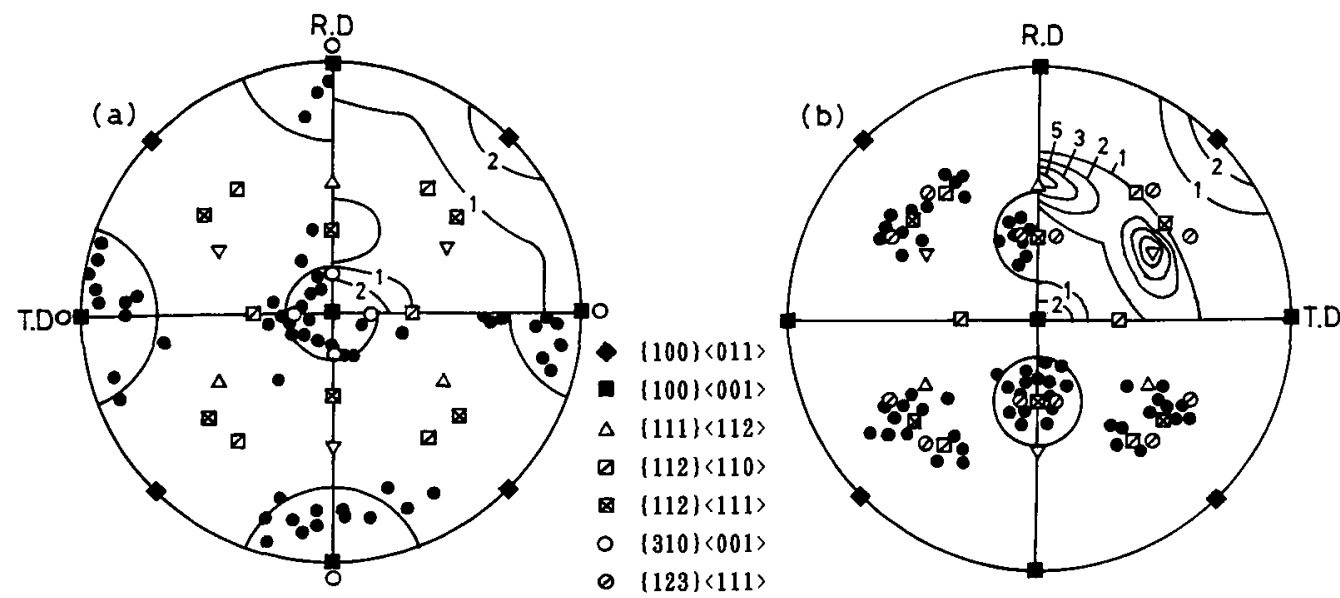

Fig.2 $\{200\}$ pole figures for primary $(-)$ and secondary $(C)$ recrystallization textures devoloped from the straight-rolled specimens with rolling reductions of $70 \%$ (a) and $90 \%$ (b).

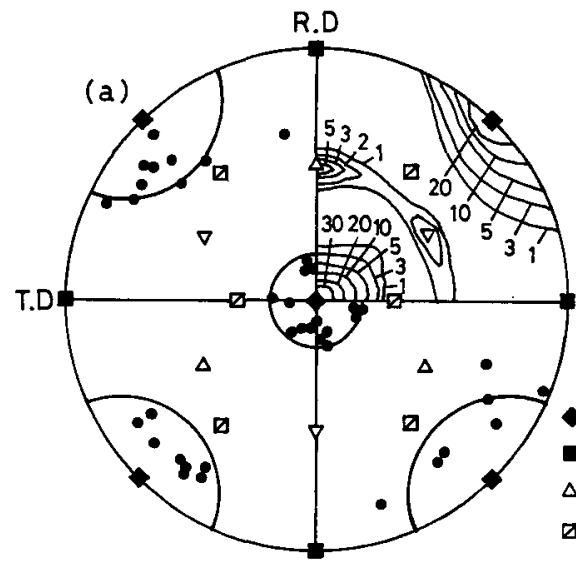

$\{100\}<011>$

- $\{100\}<001>$

$\Delta\{111\}<112\rangle$

ఐ $\{112\}\langle 110\rangle$

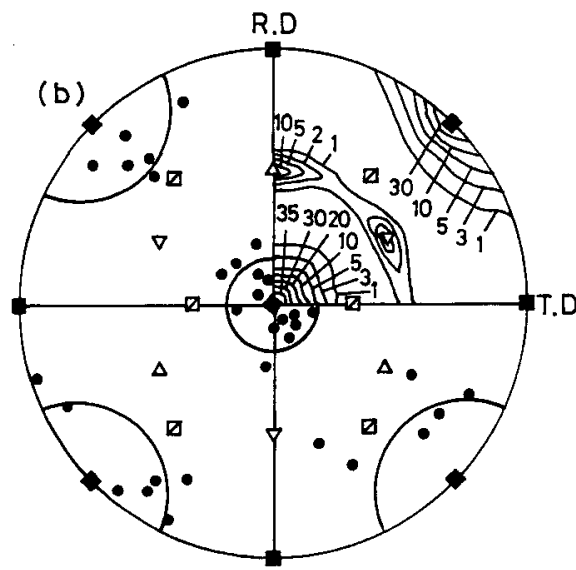

Fig.3 $\{200\}$ pole figures for primary (-) and secondary specimens with rolling reductions of $70 \%$ (a) and $90 \%$ (b).

位をあわせもつ集積度の高い方位成分によって構成さ れており，圧延率が増すことによりさらに両方位成分 の集積度も高まる傾向を示す.ク口ス圧延によって得 られた 2 次再結晶核粒方位はTable 2 の結果が示すよう に，圧延率 70\%，90\%のどちらの場合においても $\{100\}<011>$ 近傍方位が出現し, その分散度は圧延率 によって大きな相違は認められずさ20度の範囲内に集 積し，発達した方位粒として表すことができる。また， 2 次再結晶粒方位は 1 次再結晶集合組織の主成分 $\{100\}<011>$ 方位に対しておよそ20度前後隔てた位置 に分布している，従って，ストレート圧延で述べたよ うにクロス圧延の場合においても2 次再結晶粒は 1 次 再結晶集合組織の主成分から隔てた弱成分が 2 次再結
晶核粒として発達したものと考えられる. Fig.4は得ら れた 2 次再結晶核粒の優先結晶方位を圧延面に垂直な 方向 (N.D) および圧延方向 (R.D) にすべてまとめて 反転極点図に示したものである。この図から明らかな ように 2 次再結晶核粒方位はストレート圧延の場合, 圧延率70\%と $90 \%$ ではその方位分布が異なり，圧延面 方向へは両圧延率とも分散しているが, 圧延方向へは ある程度集積している。 クロス圧延では圧延率 70\%， $90 \%$ どちらの場合も圧延面および圧延方向へは同一 方位が発達し，集積した方位粒をとる。しかしながら， 圧延方法および圧延率の相違にもかかわらず圧延面方 位に $\{110\}$ 近傍方位が得難い.今後この $\{110\}$ 面方 位を得ることが急務な課題であろう.Photo.1にこのよ 
Table 1 Orientation relationship between primary and secondary recrystallized grains devoloped from the straight-rolled specimens with rolling reductions of $70 \%$ and $90 \%$.

\begin{tabular}{c|c|c}
\hline & $\begin{array}{c}\text { Primary Recrystallization } \\
\text { (Polycrystalline) }\end{array}$ & $\begin{array}{c}\text { Secondary Recrystallization } \\
\text { (Single Crysta1) }\end{array}$ \\
\hline $70 \%$ rolled & $\begin{array}{c}\text { Teak }\{100\}<011> \\
+ \text { Other Components } \\
\text { (Randam Texture) }\end{array}$ & Near $(\{100\}+\{310\})<001>$ \\
\hline $90 \%$ rolled & $\begin{array}{c}\text { Strong }\{111<<112> \\
+ \text { Neak }\{100\}<011> \\
\text { (Sharp Texture) }\end{array}$ & Near $(\{112\}+\{123\})<111>$ \\
\hline
\end{tabular}

Table 2 Orientation relationship between primary and secondary recrystallized grains devoloped from the cross-rolled specimens with rolling reductions of $70 \%$ and $90 \%$.

\begin{tabular}{l|c|c}
\hline & $\begin{array}{c}\text { Primary Recrystallization } \\
\text { (Polycrystalline) }\end{array}$ & $\begin{array}{c}\text { Secondary Recrystallization } \\
\text { (Single Crystal) }\end{array}$ \\
\hline $70 \%$ rolled & $\begin{array}{r}\text { Strong }\{100\}<011> \\
\{111\}<112> \\
(\text { Sharp Texture) }\end{array}$ & Strong $\{100\}<011> \pm 20^{\circ}$ \\
\hline $90 \%$ rolled & $\begin{array}{c}\text { Strong }\{100\}<011> \\
\{111\}<112> \\
(\text { Sharper Texture) }\end{array}$ & Strong $\{100\}<011> \pm 20^{\circ}$ \\
\hline
\end{tabular}

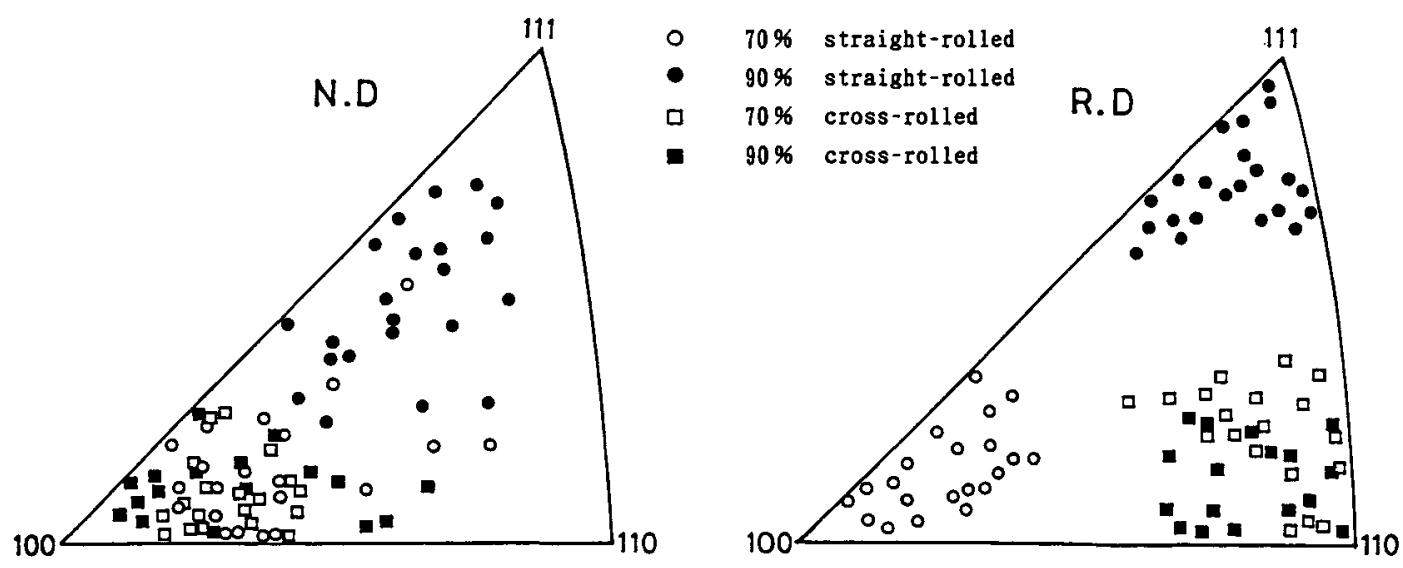

Fig.4 Orientations of secondary grains shown in a unit stereographic triangle. 
うな分布で分散した 2 次再結晶核粒の中から所望方位 粒を選択して,この核粒のみを $2000 \sim 2200^{\circ} \mathrm{C}$ の温度範 囲にて帯域焼鈍を施すことによって成長させた一例を 示す.

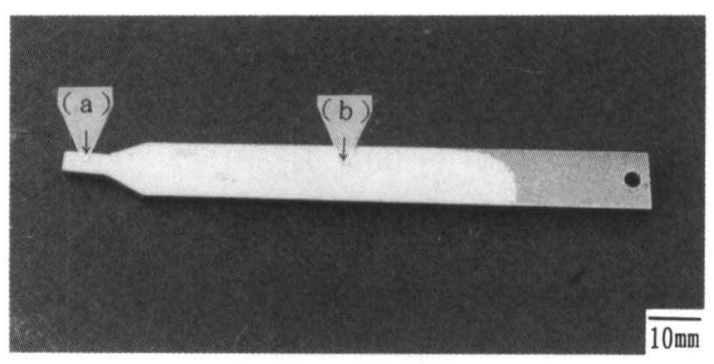

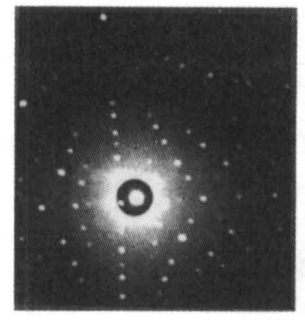

(a' )

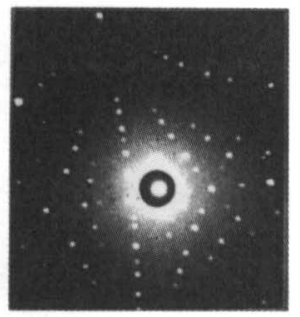

(b' )
Photo.1 Typical macrostructure of single crystal with a desired orientaion prepared by means of zone annealing. Laue pattens (a') and ( $\left.b^{\prime}\right)$ were taken from the (a) and (b) shown in the macrostructure.

この結果, 試料全体が核粒方位と同一の方位を有す る単結晶を得ることができた. (a) が選択した核粒, (b) が帯域焼鈍によって成長することにより得られた単結 晶であり,これらの結晶粒が下部に示したX線ラウエ写 真 (a')，(b') から同一方位であることが明らかである.

\section{4 結 言}

本実験では, 所望方位を有する Mo 単結晶を作製す ることを目的に, 圧延方法と圧延率を変えたドープ Mo 材を用いて帯域焼鈍を行い, 以下の結果を得た.

（1）試料端部を切り込みによって楖状に分割し, 局部 加熱することにより結晶方位の異なる 2 次再結晶 核粒を容易に得ることができた。

(2) 2 次再結晶核粒方位は, 圧延率 $70 \%$ のストレート 圧延の場合には $(\{100\}+\{310\})<001>$ 近傍方位, $90 \%$ 場合では $(\{112\}+\{123\})<111>$ 近傍方位 を中心として分散した方位粒をとり, クロス圧延 においては圧延率 $70 \%, 90 \%$ どちらの場合も
$\{100\}<011>$ 方位 20 度前後の範囲に集積した方位 粒が得られることが明らかとなった。

(3) 2 次再結晶核粒の方位は圧延方法および圧延率に よってもたらされる1次再結晶集合組織により大 きく影響を受け, 結晶学的方位関係から見れば 1 次再結晶集合組織の弱成分に相当していた.

（4）試料端部を切り込みによって櫛状に分割し, 局部 加熱することにより得られた 2 次再結晶核粒の中 から所望方位粒を選択して带域焼鈍を施すことに よって, 所望方位を有する単結晶材料の作製が可 能となった.

\section{文献}

1) T.Fujii, R.Watanabe, Y.Hiraoka and M.Okada : J.LessCommon Met., 96 (1984) 297.

2) T.Fujii, R.Watanabe, Y.Hiraoka and M.Okada : J.LessCommon Met., 97 (1984) 163.

3) T.Fujii, R.Watanabe, Y.Hiraoka and M.Okada : J.LessCommon Met., 99 (1984) 77.

4) P.I.Welch and G.J.Davies : Texture and Microstructure, 6 (1983) 21.

5) 藤井忠行, 岡本謙一：粉体および粉末冶金, 36 (1989) 819.

6) 中島正三郎, 高橋邦秀, 原勢二郎: 鉄と鋼, 80 (1994) 49.

7) 上平一茂, 本多均一, 藤井忠行: 粉体および粉末治 金, 42 (1995) 1190.

8) T.Fujii, Y.Hiraoka and R.Watanabe : U.S.Patent No.449, 1560.

9) 藤井忠行, 平岡裕, 渡辺亮治, 岡本謙一: 特許第 1688235 号.

10) T.Fujii, R.Watanabe, Y.Hiraoka and M.Okada : Met, Sci and Eng., 68 (1984) 45.

11) Y.Ohba, Y.Tamura and T.Fujii : Trans.JIM, 12 (1971) 348.

12) 長崎誠三編: 金属物理実験室, アグネ出版, (1964) 2.

13) M.Semchysen and G.A.Timmons : Trans. AIME, 194 (1952) 279.

14) J.W.Pugh : Trans. Metall. Soc. AIME, 212 (1958) 637.

15) T.Fujii and Y.Ohba : Proc. 6th ICOTOM, Tokyo, ISIJ, 1 (1981) 628.

16) 武部克嗣, 藤井忠行: 粉体および粉末治金, 36 (1989) 284. 